Hiroshi Nagata - Keiichiro Kumahara • Takuya Tomemori

Yukiko Arimoto • Kyoko Isoyama • Koh Yoshida

Akiyoshi Konno

\title{
Frequency and clinical features of patients with sensorineural hearing loss associated with the A3243G mutation of the mitochondrial DNA in otorhinolaryngic clinics
}

Received: June 1, 2001 / Accepted: July 16, 2001

\begin{abstract}
The A3243G mutation of the mitochondrial gene is a cause of maternally inherited diabetes and deafness. The aim of this study was to evaluate the frequency and clinical features of this mutation in patients with sensorineural hearing loss (SNHL) in otorhinolaryngic clinics. The frequency of the A3243G mutation in 230 patients with SNHL was $1.74 \%(4 / 230)$. Three of the four patients had diabetes mellitus (DM) and were already aware that they had the mutation. The other had cardiomyopathy but not DM, and proved to have the mutation in this study. The frequency of the mutation was $12.9 \%$ (4/31) in patients with a family history of possible maternal inheritance of SNHL, $10.3 \%(3 / 29)$ in patients with DM, and 50\% (3/6) in patients with both. The age of onset of SNHL in these patients and their families was between their teens and their forties. The chance of diagnosing the A3243G mutation in patients with SNHL in otorhinolaryngic clinics is probably less than $1 \%$. Association of DM, cardiomyopathy, a family history of possible maternal inheritance of SNHL, and an onset of SNHL between the teens and the forties are signs suggesting the mutation. These signs provide us with a reason for genetic testing for the mutation.
\end{abstract}

Key words Mitochondrial DNA · Point mutation · Genetic test - Sensorineural hearing loss - Diabetes mellitus · Cardiomyopathy

\section{Introduction}

Heteroplasmic mutations of the mitochondrial DNA (mtDNA) are important causes of maternally inherited diseases. Variability in the level of mutant mtDNA in tissues as

H. Nagata $(\bowtie) \cdot$ K. Kumahara · T. Tomemori · Y. Arimoto

K. Isoyama $\cdot$ K. Yoshida $\cdot$ A. Konno

Department of Otorhinolaryngology (J2), Graduate School of

Medicine, Chiba University, 1-8-1 Inohana, Chuoh-ku, Chiba

260-8670, Japan

Tel. +81-43-222-7171; Fax +81-43-227-3442

e-mail: nagatah@ho.chiba-u.ac.jp well as in individuals is believed to explain the diversity of clinical manifestations associated with identical mtDNA mutations. One such mutation potentially associated with various clinical syndromes is the $A$ to $G$ point mutation at nucleotide position 3243 (A3243G) in the mitochondrial tRNA $^{\text {Leu(UUR) }}$ gene. This mutation was first identified in patients with MELAS (mitochondrial myopathy, encephalopathy, lactic acidosis, and stroke-like episodes) syndrome (Goto et al. 1990). Subsequent work showed that the identical mutation is also causative for maternally inherited diabetes associated with deafness (Kadowaki et al. 1994; van den Ouweland et al. 1992, 1994), and the name MIDD (maternally inherited diabetes and deafness) was proposed for this syndrome (van den Ouweland et al. 1994, 1995). Furthermore, the A3243G mutation was shown to be a cause of an overlapping syndrome of MERRF (myoclonic epilepsy with ragged-red fibers) and PEO (progressive external ophthalmoplegia) (Verma et al. 1996), PEO (Koga et al. 2000; Pang et al. 1999), Kearns-Sayre syndrome (Pang et al. 1999), Leigh syndrome (Koga et al. 2000), progressive nondiabetic kidney disease (Cheong et al. 1999; Jansen et al. 1997), and cardiac diseases (Shiotani et al. 1998; Yamagata et al. 2000).

Majamaa et al. (1998) studied an adult population of 245,201 individuals, and screened for the A3243G mutation in 480 selected subjects who had one or more of following diseases: diabetes mellitus (DM), sensorineural hearing impairment, epilepsy, occipital brain infarct, ophthalmoplegia, cerebral white-matter disease, basal-ganglia calcifications, hypertrophic cardiomyopathy, or ataxia. They found the mutation in 11 pedigrees, and clinical evaluation of the probands revealed that the most frequent syndrome consisted of hearing impairment, cognitive decline, and short stature. Damian et al. (1995) studied a large pedigree with the A3243G mutation and analyzed clinical manifestations in 26 cases positive for the mutation but unassociated with stroke-like episodes. They observed hearing impairment in 15 cases, diabetes in 6 cases, nephropathy in 7 cases, mild myopathy in 4 cases, cardiomyopathy in 2 cases, cerebellar diseases in 4 cases, mental retardation in 2 cases, and 8 cases were asymptomatic. Thus, these studies suggest that hear- 
ing impairment is probably the most frequent symptom associated with the $\mathrm{A} 3243 \mathrm{G}$ mutation.

However, studies on the frequency of patients with the A3243G mutation in otorhinolaryngic clinics are limited (Usami et al. 2000), whereas there have been many studies on the frequency of the mutation in diabetes clinics (Elbein and Hoffman 1996; Fukui et al. 1997; Fukunaga et al. 1997; Holmes-Walker and Boyages 1999; Kadowaki et al. 1994; Katagiri et al. 1994; Newkirk et al. 1997; Odawara et al. 1995; Otabe et al. 1994; Rigoli et al. 1997; Shigemoto et al. 1998; Vionnet et al. 1993). Thus, the significance of this mutation in clinical practice in an otorhinolaryngic clinic appears to have not been determined. The aim of this study is to evaluate the frequency of the mutation among routine hospital patients who visited otorhinolaryngic clinics for hearing impairment, and to clarify the importance and clinical features of this mutation in otorhinolaryngic clinics.

\section{Subjects and methods}

\section{Subjects}

Two hundred and thirty subjects with bilateral sensorineural hearing loss (SNHL) were enrolled for this study. The SNHL in the patients was of unknown etiology, or probably was associated with presbycusis in the most senile patients. Patients with other known etiology such as sudden deafness, drug-induced hearing impairment, acoustic trauma, Meniere's disease, etc., were excluded from this study. All of the subjects were unrelated Japanese residents of the Tokyo area, primarily Chiba Prefecture, adjacent of Tokyo. They were outpatients of otorhinolaryngic clinics of Chiba University Hospital or affiliated hospitals. All patients were subjected to measurement of hearing levels by pure-tone audiometry. The age at onset of hearing impairment was defined as the time when a patient was conscious of hearing loss or the time when it was diagnosed by audiometry. The judgment for association with DM was made on the basis of a history of diagnosis and treatment of DM, or the patients were evaluated for DM by measuring the level of fasting serum sugar and/or hemoglobin $\mathrm{A}_{1 \mathrm{C}}$. The patients were asked about the presence of a history of other diseases such as cardiac and kidney diseases. A family history was elicited for hearing impairment, DM, and neuromuscular diseases, and the possibility of maternal transmission of these was estimated. This study was approved by the ethics committee of the Graduate School of Medicine, Chiba University.

\section{Analysis of the A3243G mutation of mtDNA}

A restriction endonuclease fragment polymorphism of a polymerase chain reaction product (PCR-RFLP) was used for analysis of the A3243G mutation. Genomic DNA extracted from peripheral blood was amplified by polymerase chain reaction (PCR) with primers 5'-ACGAAAGGA CAAGAGAAATAAGGCC-3' [3125-3149; all nucleotide

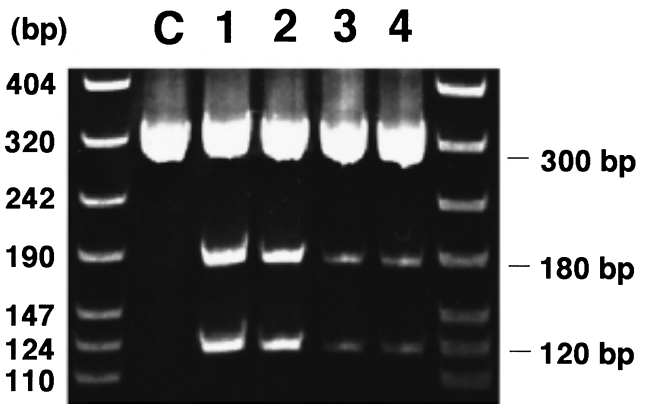

Fig. 1. Polymerase chain reaction-restriction fragment length polymorphism analysis with Apa I for the A3243G mutation of the mitochondrial gene. Lanes 1 to 4 are digested polymerase chain reaction products from patients 1 to 4 in Table 2 . The percentage of mutant DNA in each patient was $41.1 \%, 36.1 \%, 19.0 \%$, and $20.0 \%$, respectively. Lane $C$ is a negative control for the mutation. The size marker is molecular weight marker VIII (Roche Diagnostic, Mannheim, Germany)

positions in the text are according to Anderson et al. (1981)] and 5'-CCACGTTGGGGCCTTTGCGTAG-3' (34243403 ) to incorporate the $\mathrm{A} 3243 \mathrm{G}$ site into the PCR product. PCR was performed with reagents composed of $200 \mathrm{nmol} / 1$ primers, $150 \mu \mathrm{mol} / 1 \mathrm{dNTPs}, 20 \mathrm{mmol} / 1 \mathrm{Tris} \mathrm{HCl}$ at $\mathrm{pH} 8.4$, $50 \mathrm{mmol} / 1 \mathrm{KCl}, 1.5 \mathrm{mmol} / 1 \mathrm{MgCl} 2$, and 1.5 units Taq DNA polymerase in a $100-\mu l$ reaction solution. The program was $94^{\circ} \mathrm{C}$ for $1 \mathrm{~min}, 55^{\circ} \mathrm{C}$ for $1 \mathrm{~min}$, and $72^{\circ} \mathrm{C}$ for $1 \mathrm{~min}$ for 35 cycles. The PCR product was precipitated with $20 \mu \mathrm{g}$ of glycogen (Roche Diagnostic, Mannheim, Germany), dissolved in $35 \mu \mathrm{l}$ of distilled water, and $10 \mu \mathrm{l}$ of the resulting solution was digested with $10 \mathrm{U}$ of Apa I (TAKARA, Kyoto, Japan) at $37^{\circ} \mathrm{C}$ overnight. Digested fragments were separated on a $6 \%$ polyacrylamide gel. The size of the PCR product was $300 \mathrm{bp}$, and digested fragments cleaved at the A $3243 \mathrm{G}$ site were $180 \mathrm{bp}$ and $120 \mathrm{bp}$ long. PCR products from the wild-type DNA were not cut with Apa I (Fig. 1). The results of the analysis were confirmed by direct sequencing of PCR products positive and negative for the A3243G mutation. In addition, the intensity of bands was assessed with a densitometer (Molecular Dynamics, Sunnyvale, CA, USA), and the percentage of mutant DNA was calculated.

\section{Results}

The method used in this study clearly and constantly detected the $\mathrm{A} 3243 \mathrm{G}$ mutation when the percentage of mutant DNA was more than $10 \%$ in the total mtDNA in peripheral blood leukocytes (data not shown). The frequency of the A3243G mutation of the mtDNA in the 230 subjects with SNHL in our otorhinolaryngic clinics was $1.74 \%(4 / 230)$ (Table 1$)$; the percentage of mutant DNA was $41.1 \%, 36.1 \%, 19.0 \%$, and $20.0 \%$ in the four patients (Fig. 1). Among the 230 patients, 54 had family histories of SNHL in which family members with hearing impairment appeared in at least two consecutive generations, and 31 of the 54 families were considered to have family histories of 
possible maternal inheritance of SNHL, i.e., they could not be precisely judged to have maternal or autosomal dominant inheritance of SNHL. All four patients with the mutation had family histories of SNHL that were consistent with maternal inheritance (Tables 1,2). In terms of association with other diseases, three of the four had DM, and the other had hypertrophic cardiomyopathy but not DM. The frequency of the mutation proved to be as high as $12.9 \%(4 / 31)$ in patients with a family history of possible maternal inheritance of SNHL, $10.3 \%(3 / 29)$ in patients associated with $\mathrm{DM}$, and $50 \%(3 / 6)$ in patients with both (Table 1).

Three of the four patients were already aware that they had the mutation, but the other (case 1) was not (Table 2). Two of the three patients who had known of their mutations were also aware from genetic counseling at diabetes clinics that their SNHL and DM were due to the mutation. The third patient (case 4) had been asymptomatic for DM until visiting our clinic for evaluation of SNHL and was subsequently diagnosed as having glucose intolerance (Table 2).

The age of onset of SNHL in these patients with the A3243G mutation was the twenties (one patient), the thirties (two patients), and the forties (one patient) (Tables 1 , 2). The onset of SNHL in their families was between the teens and the forties, except for one subject with MELAS and SNHL, who developed SNHL before the age of ten (Table 2).

Table 1. Summary of patients with SNHL analyzed for the A3243G mutation of mtDNA

\begin{tabular}{lll}
\hline $\begin{array}{l}\text { Age of onset of } \\
\text { SNHL (year) }\end{array}$ & $\begin{array}{l}\text { Number of patients studied } \\
\text { (with DM / with MI / } \\
\text { with DM \& MI) }\end{array}$ & $\begin{array}{l}\text { Number of } \\
\text { patients with } \\
\text { A3243G mutation }\end{array}$ \\
\hline $0-9$ & $39(1 / 3 / 0)$ & 0 \\
$10-19$ & $29(3 / 6 / 0)$ & 0 \\
$20-29$ & $23(0 / 5 / 0)$ & $1^{\text {a }}$ \\
$30-39$ & $20(5 / 7 / 3)$ & $2^{\text {b }}$ \\
$40-49$ & $37(3 / 6 / 2)$ & $1^{\text {b }}$ \\
$50-$ & $82(17 / 4 / 1)$ & 0 \\
total & $230(29 / 31 / 6)$ & 4
\end{tabular}

SNHL, sensorineural hearing loss; MI, a family history of possible maternal inheritance of SNHL; DM, diabetes mellitus

${ }^{a}$ This patient did not have DM but had cardiomyopathy

${ }^{\mathrm{b}}$ These three patients had DM

\section{Discussion}

The present study describes the frequency and clinical features of patients with the $\mathrm{A} 3243 \mathrm{G}$ mutation of mtDNA in our otorhinolaryngic clinics. The frequency of the mutation in the 230 subjects was $1.74 \%$ (4/230). Among the four patients with the mutation, three were already aware that they had the mutation, and the fourth was shown to be positive for it for the first time in this study. Thus, the frequency of the mutation in patients with SNHL in this study would have been $0.440 \%(1 / 227)$ if patients previously diagnosed to be positive for the mutation had been excluded from the study. This frequency is comparable with that recently reported by Usami et al. (2000); they reported that the frequency of the $\mathrm{A} 3243 \mathrm{G}$ mutation in 319 unrelated Japanese patients with hearing impairment was $0.314 \%$ $(1 / 319)$. These results showed that there were patients visiting otorhinolaryngic clinics for SNHL who were not aware that they had the A3243G mutation, although the frequency of the mutation was not very high. Therefore, in order to perform a genetic test for the A3243G mutation in otorhinolaryngic clinics reasonably, we must know the signs that suggest the mutation.

In the present study, we focused our attention on the association with DM as well as a family history of maternal inheritance of SNHL among the subjects because previous reports from diabetes clinics have shown that most patients with the A3243G mutation presented with DM and SNHL, and MIDD syndrome appears to be an established disease category (Maassen et al. 1996; Maassen and Kadowaki 1996). In addition, SNHL in Japanese patients in otorhinolaryngic clinics previously reported to be due to the A3243G mutation was associated with DM (Oshima et al. 1996; Tamagawa et al. 1997; Usami et al. 2000; Yamasoba et al. 1996). The present results showed that all four patients with the mutation had family histories of maternal inheritance of SNHL, and three of the four cases were also associated with DM. The frequency of the mutation proved to be as high as $12.9 \%(4 / 31)$ in patients with a family history of possible maternal inheritance of SNHL, 10.3\% (3/29) in patients with $\mathrm{DM}$, and $50 \%(3 / 6)$ in patients with both. Therefore, it is apparent that a family history of possible

Table 2. Clinical features of patients with SNHL due to the A3243G mutation of mtDNA

\begin{tabular}{|c|c|c|c|c|c|}
\hline $\begin{array}{l}\text { Case } \\
\text { No. }\end{array}$ & $\begin{array}{l}\text { Age of onset } \\
\text { of SNHL }\end{array}$ & Sex & $\mathrm{DM}$ & Family history & Remarks \\
\hline 1 & 22 & M & - & $\begin{array}{l}\text { Mother had SNHL } \\
\text { but not DM } \\
\text { (Onset: forties) }\end{array}$ & $\begin{array}{l}\text { Proved to be positive for the A } 3243 \mathrm{G} \text { mutation in this study } \\
\text { Died of hypertrophic cardiomyopathy at age of } 28\end{array}$ \\
\hline 2 & 35 & M & + & $\begin{array}{l}\text { Mother had SNHL and } \\
\text { DM (Onset: forties) }\end{array}$ & $\begin{array}{l}\text { Previously diagnosed as having the A3243G mutation at a } \\
\text { diabetes clinic }\end{array}$ \\
\hline 3 & 30 & $\mathrm{~F}$ & + & $\begin{array}{l}\text { Daughter and son had } \\
\text { SNHL and DM } \\
\text { (Onset: teens) }\end{array}$ & $\begin{array}{l}\text { Previously diagnosed as having the A } 3243 \mathrm{G} \text { mutation at a } \\
\text { diabetes clinic }\end{array}$ \\
\hline 4 & 46 & $\mathrm{~F}$ & + & $\begin{array}{l}\text { Daughter had MELAS } \\
\text { and SNHL but not DM } \\
\text { (Onset: before puberty) }\end{array}$ & $\begin{array}{l}\text { Previously diagnosed as having the A3243G mutation at a } \\
\text { neurology clinic for her daughter } \\
\text { Presented with SNHL and subsequently diagnosed as having } \\
\text { glucose intolerance }\end{array}$ \\
\hline
\end{tabular}


maternal inheritance of SNHL and association with DM are possible signs of the $\mathrm{A} 3243 \mathrm{G}$ mutation in otorhinolaryngic clinics as well as in diabetes clinics. However, in a few cases in those previous reports, the onset of SNHL preceded that of DM (Tamagawa et al. 1997; Yamasoba et al. 1996), raising the possibility that these patients might have visited an otorhinolaryngic clinic before the presentation of DM. In addition, we herein report a case unassociated with DM (case 1). Thus, we must bear in mind that patients with SNHL due to the A3243G mutation may not always present with DM. Moreover, one patient proved to have glucose intolerance after the diagnosis of SNHL (case 4), suggesting that we may need to screen for DM in a certain population with SNHL.

Because of heteroplasmy, the proportion of mutant mtDNA varies in cells/tissues of an individual and in different members of the same family, and affected organs can be variable in patients with the $\mathrm{A} 3243 \mathrm{G}$ mutation. In the present study, one patient (case 1), who had the A3243G mutation at a relatively high percentage in mtDNA in leukocytes, had SNHL and cardiomyopathy but not DM. Cardiac involvement has been reported in patients with the mutation and DM/SNHL (Shiotani et al. 1998; Yamagata et al. 2000). Another organ that has been relatively frequently reported to be involved in patients with the mutation is the kidney (Cheong et al. 1999; Nakamura et al. 1999; van den Ouweland et al. 1999). Therefore, before a genetic test for the A3243G mutation is suggested, patients with SNHL should be interviewed about cardiopathy or kidney disease as well as DM.

In terms of the age at onset of SNHL, all patients in this study and their family members with SNHL, but without MELAS, began to recognize hearing impairment between their teens and their forties. Previous reports on 12 Japanese patients with SNHL due to the A3243G mutation but without MELAS showed that 10 patients showed the onset of hearing impairment between their twenties and their forties, and 1 patient, who also had chronic otitis media, experienced the onset of hearing loss at the age of 18 , and 1 patient experienced the onset of SNHL at the age of 55 following the onset of DM at the age of 46 (Oshima et al. 1996; Tamagawa et al. 1997; Yamasoba et al. 1996). Thus, the present study, together with the previous reports, suggests that an age of onset of hearing impairment between the teens and the forties is a sign suggesting the A3243G mutation.

In conclusion, the chance of diagnosing the A3243G mutation in patients with SNHL in an otorhinolaryngic clinic appears to be less than $1 \%$. Association of DM and/or cardiac disorders and a family history of possible maternal inheritance of SNHL are signs suggesting the mutation and thus appear to provide us with a reason for a genetic test. However, we should be aware that a patient with the mutation may present without these signs. An additional sign for the mutation is an age of onset of SNHL between the teens and the forties. Therefore, patients who developed SNHL between these ages need to be interviewed carefully if they have DM or cardiac symptoms, or another disease such as kidney disease.
Acknowledgments The authors thank Drs. Takashi Kanda, Hisashi Asano, Takeshi Hino, Fumiyo Kudoh, and Yoshimi Sasamura for their cooperation in this study.

\section{References}

Anderson S, Bankier AT, Barrell BG, de Bruijn MH, Coulson AR, Drouin J, Eperon IC, Nierlich DP, Roe BA, Sanger F, Schreier PH, Smith AJ, Staden R, Young IG (1981) Sequence and organization of the human mitochondrial genome. Nature 290:457-465

Cheong HI, Chae JH, Kim JS, Park HW, Ha IS, Hwang YS, Lee HS, Choi Y (1999) Hereditary glomerulopathy associated with a mitochondrial tRNA ${ }^{\text {Leu }}$ gene mutation. Pediatr Nephrol 13:477-480

Damian MS, Seibel P, Reichmann H, Schachenmayr W, Laube H, Bachmann G, Wassill KH, Dorndorf W (1995) Clinical spectrum of the MELAS mutation in a large pedigree. Acta Neurol Scand 92:409-415

Elbein SC, Hoffman MD (1996) Role of mitochondrial DNA tRNA leucine and glucagon receptor missense mutations in Utah white diabetic patients. Diabetes Care 19:507-508

Fukui M, Nakano K, Obayashi H, Kitagawa Y, Nakamura N, Mori H, Kajiyama S, Wada S, Fujii M, Yoshimori K, Kanaitsuka T, Shigeta H, Kondo M (1997) High prevalence of mitochondrial diabetes mellitus in Japanese patients with major risk factors. Metabolism 46:793-795

Fukunaga Y, Azuma N, Koshiyama H, Inoue D, Sato H, Yoshimasa Y, Nakao K (1997) Mitochondrial DNA 3243 mutation is infrequent in Japanese diabetic patients with auditory disturbance. Diabetes Care 20:1800-1803

Goto Y, Nonaka I, Horai S (1990) A mutation in the tRNA ${ }^{\text {Leu(UUR) }}$ gene associated with the MELAS subgroup of mitochondrial encephalomyopathies. Nature 348:651-653

Holmes-Walker DJ, Boyages SC (1999) Prevalence of maternally inherited diabetes and deafness in Australian diabetic subjects. Diabetologia 42:1028-1029

Jansen JJ, Maassen JA, van der Woude FJ, Lemmink HA, van den Ouweland JM, t' Hart LM, Smeets HJ, Bruijn JA, Lemkes HH (1997) Mutation in mitochondrial tRNA ${ }^{\text {Leu(UUR) }}$ gene associated with progressive kidney disease. J Am Soc Nephrol 8:1118-1124

Kadowaki T, Kadowaki H, Mori Y, Tobe K, Sakuta R, Suzuki Y, Tanabe Y, Sakura H, Awata T, Goto Y, Hayakawa T, Matsuoka K, Kawamori R, Kamada T, Horai S, Nonaka I, Hagura R, Akanuma Y, Yazaki Y (1994) A subtype of diabetes mellitus associated with a mutation of mitochondrial DNA. N Engl J Med 330:962-968

Katagiri H, Asano T, Ishihara H, Inukai K, Anai M, Yamanouchi T, Tsukuda K, Kikuchi M, Kitaoka H, Ohsawa N, Yazaki Y, Oka Y (1994) Mitochondrial diabetes mellitus: prevalence and clinical characterization of diabetes due to mitochondrial tRNA ${ }^{\mathrm{Leu}(\mathrm{UUR})}$ gene mutation in Japanese patients. Diabetologia 37:504-510

Koga Y, Akita Y, Takane N, Sato Y, Kato H (2000) Heterogeneous presentation in A3243G mutation in the mitochondrial tRNA ${ }^{\text {Leu(UUR) }}$ gene. Arch Dis Child 82:407-411

Maassen JA, Kadowaki T (1996) Maternally inherited diabetes and deafness: a new diabetes subtype. Diabetologia 39:375-382

Maassen JA, Jansen JJ, Kadowaki T, van den Ouweland JM, Hart LM, Lemkes HH (1996) The molecular basis and clinical characteristics of Maternally Inherited Diabetes and Deafness (MIDD), a recently recognized diabetic subtype. Exp Clin Endocrinol Diabetes 104:205211

Majamaa K, Moilanen JS, Uimonen S, Remes AM, Salmela PI, Karppa M, Majamaa-Voltti KA, Rusanen H, Sorri M, Peuhkurinen KJ, Hassinen IE (1998) Epidemiology of A3243G, the mutation for mitochondrial encephalomyopathy, lactic acidosis, and strokelike episodes: prevalence of the mutation in an adult population. Am J Hum Genet 63:447-454

Nakamura S, Yoshinari M, Doi Y, Yoshizumi H, Katafuchi R, Yokomizo Y, Nishiyama K, Wakisaka M, Fujishima M (1999) Renal complications in patients with diabetes mellitus associated with an A to $\mathrm{G}$ mutation of mitochondrial DNA at the 3243 position of leucine tRNA. Diabetes Res Clin Pract 44:183-189

Newkirk JE, Taylor RW, Howell N, Bindoff LA, Chinnery PF, Alberti KG, Turnbull DM, Walker M (1997) Maternally inherited diabetes 
and deafness: prevalence in a hospital diabetic population. Diabetic Med 14:457-460

Odawara M, Sasaki K, Yamashita K (1995) Prevalence and clinical characterization of Japanese diabetes mellitus with an A-to-G mutation at nucleotide 3243 of the mitochondrial tRNA ${ }^{\text {Leu(UUR) }}$ gene. J Clin Endocrinol Metab 80:1290-1294

Oshima T, Ueda N, Ikeda K, Abe K, Takasaka T (1996) Bilateral sensorineural hearing loss associated with the point mutation in mitochondrial genome. Laryngoscope 106:43-48

Otabe S, Sakura H, Shimokawa K, Mori Y, Kadowaki H, Yasuda K, Nonaka K, Hagura R, Akanuma Y, Yazaki Y, Kadowaki T (1994) The high prevalence of the diabetic patients with a mutation in the mitochondrial gene in Japan. J Clin Endocrinol Metab 79:768-771

Pang CY, Huang CC, Yen MY, Wang EK, Kao KP, Chen SS, Wei YH (1999) Molecular epidemiologic study of mitochondrial DNA mutations in patients with mitochondrial diseases in Taiwan. J Formos Med Assoc 98:326-334

Rigoli L, Di Benedetto A, Romano G, Corica F, Cucinotta D (1997) Mitochondrial DNA [tRNA ${ }^{\mathrm{Leu}(\mathrm{UUR})}$ ] mutation in a southern Italian diabetic population. Diabetes Care 20:674-675

Shigemoto M, Yoshimasa Y, Yamamoto Y, Hayashi T, Suga J, Inoue G, Okamoto M, Jingami H, Tsuda K, Yamamoto T, Yagura T, Oishi M, Tsujii S, Kuzuya H, Nakao K (1998) Clinical manifestations due to a point mutation of the mitochondrial tRNA ${ }^{\text {leu(UUR) }}$ gene in five families with diabetes mellitus. Internal Med 37:265-272

Shiotani H, Ueno H, Inoue S, Yokota Y, Yokoyama M (1998) Diabetes mellitus and cardiomyopathy - association with mutation in the mitochondrial tRNA ${ }^{\text {Leu(UUR) }}$ gene. Jpn Circ J 62:309-310

Tamagawa Y, Kitamura K, Hagiwara H, Ishida T, Nishizawa M, Saito T, Iwamoto Y (1997) Audiologic findings in patients with a point mutation at nucleotide 3243 of mitochondrial DNA. Ann Otol Rhinol Laryngol 106:338-342

Usami S, Abe S, Akita J, Namba A, Shinkawa H, Ishii M, Iwasaki S, Hoshino T, Ito J, Doi K, Kubo T, Nakagawa T, Komiyama S, Tono T, Komune S (2000) Prevalence of mitochondrial gene mutations among hearing impaired patients. J Med Genet 37:38-40 van den Ouweland JM, Lemkes HH, Ruitenbeek W, Sandkuijl LA, de Vijlder MF, Struyvenberg PA, van de Kamp JJ, Maassen JA (1992) Mutation in mitochondrial tRNA ${ }^{\mathrm{Lu}(\mathrm{UUR})}$ gene in a large pedigree with maternally transmitted type II diabetes mellitus and deafness. Nat Genet 1:368-371

van den Ouweland JM, Lemkes HH, Trembath RC, Ross R, Velho G, Cohen D, Froguel P, Maassen JA (1994) Maternally inherited diabetes and deafness is a distinct subtype of diabetes and associates with a single point mutation in the mitochondrial tRNA ${ }^{\text {Leu(UUR) }}$ gene. Diabetes 43:746-751

van den Ouweland JM, Lemkes HH, Gerbitz KD, Maassen JA (1995) Maternally inherited diabetes and deafness (MIDD): a distinct subtype of diabetes associated with a mitochondrial tRNA ${ }^{\text {Leu(UUR) }}$ gene point mutation. Muscle Nerve 3:S124-S130

van den Ouweland JM, Maechler P, Wollheim CB, Attardi G, Maassen JA (1999) Functional and morphological abnormalities of mitochondria harbouring the tRNA ${ }^{\text {Leu(UUR) }}$ mutation in mitochondrial DNA derived from patients with maternally inherited diabetes and deafness (MIDD) and progressive kidney disease. Diabetologia 42:485492

Verma A, Moraes CT, Shebert RT, Bradley WG (1996) A MERRF/ PEO overlap syndrome associated with the mitochondrial DNA 3243 mutation. Neurology 46:1334-1336

Vionnet N, Passa P, Froguel P (1993) Prevalence of mitochondrial gene mutations in families with diabetes mellitus. Lancet 342:14291430

Yamagata K, Tomida C, Umeyama K, Urakami K, Ishizu T, Hirayama K, Gotoh M, Iitsuka T, Takemura K, Kikuchi H, Nakamura H, Kobayashi M, Koyama A (2000) Prevalence of Japanese dialysis patients with an A-to-G mutation at nucleotide 3243 of the mitochondrial tRNA $^{\text {Leu(UUR) }}$ gene. Nephrol Dial Transplant 15:385388

Yamasoba T, Oka Y, Tsukuda K, Nakamura M, Kaga K (1996) Auditory findings in patients with maternally inherited diabetes and deafness harboring a point mutation in the mitochondrial transfer RNA $^{\text {Leu(UUR) }}$ gene. Laryngoscope 106:49-53 